\title{
Preparation and Characterization of Polyoxetane Resins Anchoring the Pendant Spacer-Separated Hydroxamic Acid Residue
}

\author{
Yao-Hua Xu, Hiroshi OGawa, Shigeyoshi KanOH, and Masatoshi MotoI \\ Department of Chemistry and Chemical Engineering, Faculty of Engineering, \\ Kanazawa University, 2-40-20 Kodatsuno, Kanazawa 920-8667, Japan
}

(Received July 6, 1998)

\begin{abstract}
Polyoxetane resins, IVa and IVb, anchoring the hydroxamic acid residue were prepared with high degree of functionality (DF) by polymer reactions from aliphatic $\mathrm{NH}_{2}$ groups at pendant spacer-ends of IIa and IIb. The pendant hydroxamic acids adsorbed $\mathrm{Cu}$ (II) ions from aqueous solution of $\mathrm{Cu}$ (II) acetate at $\mathrm{pH} 6$ to show capacity beyond that calculated for the ordinary $\mathrm{Cu}(\mathrm{II})$-complex chelated with the two pendant ligands, probably due to the formation of uncompleted chelate structures. The corresponding aromatic $\mathrm{NH}_{2}$ groups of IIc and IId showed very low DF in the same polymer reactions. At pH 6, amines of IIc and IId adsorbed $\mathrm{Cu}$ (II) ions to a certain extent, although those of IIa and IIb could adsorb no Cu(II) ions. A soft, expansible polyoxetane network, as a supporting matrix, may importantly affect $\mathrm{Cu}$ (II)-adsorption at high capacity.

KEY WORDS Cationic Ring-Opening Polymerization / Polyoxetanes / Polymer Reaction / Pendant Hydroxamic Acid/Chelating Resins /
\end{abstract}

We prepared polyoxetane resins and studied applications to functional polymers. ${ }^{1}$ For one pendant spacerseparated functional group of the resins, we prepared primary amines, such as alkylamine and aniline moieties, regarded as an important reaction site for chemically modifying resins. ${ }^{2,3}$

We are interested in chelating resins, since they are convenient adsorbents for selective removal and recovery of heavy metals useful or undesirable for living organisms. A hydroxamic acid group has chelating ability with heavy metals, and several chelating resins were prepared using pendant groups, such as $\mathrm{CO}_{2} \mathrm{CH}_{3}$, $\mathrm{CONH}_{2}$, and $\mathrm{CH}\left(\mathrm{CO}_{2} \mathrm{C}_{2} \mathrm{H}_{5}\right)_{2}$, of polyvinyl and polystyrene backbones. ${ }^{4-6}$ In our synthesis and characterization of functional polyoxetanes, we prepared polyoxetane resin anchoring a pendant hydroxamic acid group through a moderately long spacer arm, since we considered that the flexible and somewhat polar polyoxetane networks are applicable to supporting matrices of chelating resins, i.e., these resins are pressed to smoothly change conformation of polymer backbones so as to chelate with metal ions, and often used in aqueous media dissolving metal ions. The above polymer reactions may smoothly proceed due to the desired character of polyoxetane matrices. Herein, we describe the preparation and characterization of several chelating resins anchoring pendant hydroxamic acid groups, derived by polymer reaction from the pendant primary amines of cross-linked polyoxetanes.

\section{RESULTS AND DISCUSSION}

\section{Preparation of Resins Anchoring Pendant Spacer- Separated Hydroxamic Acid Residue}

As shown in Scheme 1, polyoxetane resins with pendant primary amines were obtained by $\mathrm{BF}_{3}$-initiated cationic ring-opening polymerization of imide-containing monomers, 1a-1d, with cross-linking agent, 2, followed by complete conversion of the imide moieties by hydrazinolysis or hydrolysis into amino ones, as previously reported, ${ }^{2,3}$ and the resulting resins are listed
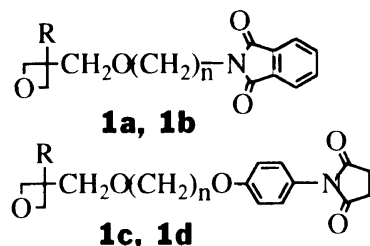

\begin{tabular}{c|cc} 
& $\mathrm{R}$ & $\mathrm{n}$ \\
\hline $\mathbf{a}$ & $\mathrm{CH}_{3}$ & 4 \\
b & $\mathrm{CH}_{3}$ & 6 \\
c & $\mathrm{CH}_{3}$ & 4 \\
d & $\mathrm{C}_{2} \mathrm{H}_{5}$ & 4
\end{tabular}<smiles>CCOCCOCCO</smiles>

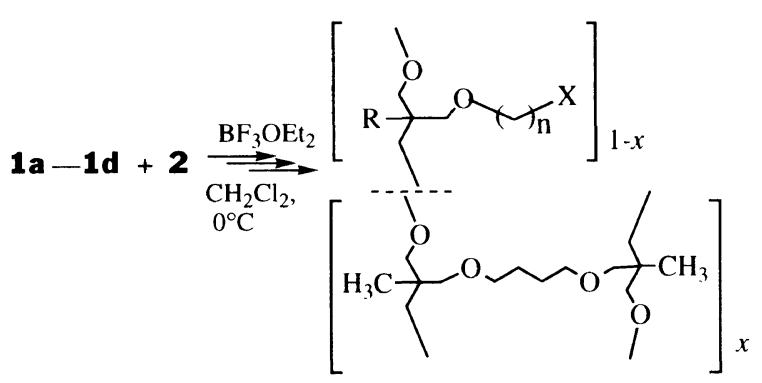

la, Ib: $X=$ phthalimido

Ic, Id: $X=4$-succinimidophenoxy

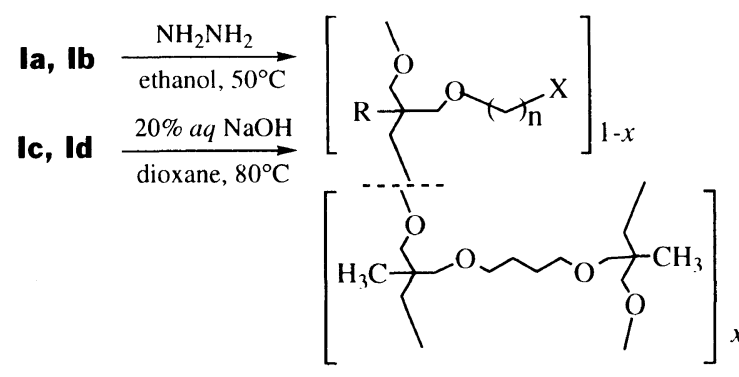

Ila, Ilb: $\mathrm{X}=\mathrm{NH}_{2}$

Ilc, IId: $X=4$-aminophenoxy

Scheme 1. Synthetic routes of polyoxetane resins, Ia-d and IIa-d from oxetanes, $\mathbf{1 a - d}$ and $\mathbf{2}$. 
Table I. Preparation of polyoxetane resins, IIa $-\mathbf{d}$, anchoring pendant amino groups and imide-protected derivatives, $\mathbf{I a}-\mathbf{d}$

\begin{tabular}{|c|c|c|c|c|c|c|c|}
\hline \multirow{3}{*}{$\begin{array}{l}\text { Monomers } \\
\text { in feed }^{\mathrm{a}}\end{array}$} & \multirow{3}{*}{$R^{b}$} & \multirow{3}{*}{$\begin{array}{c}n \text { in } \\
\text { spacer }^{\mathrm{b}}\end{array}$} & \multirow{3}{*}{$\mathrm{X}^{\mathrm{b}}$} & \multicolumn{2}{|c|}{ Polymer products } & \multicolumn{2}{|c|}{ Amine polymers } \\
\hline & & & & \multirow{2}{*}{ Name } & Yield $^{\mathrm{c}}$ & \multirow{2}{*}{ Name } & Yield $^{\mathrm{d}}$ \\
\hline & & & & & $\%$ & & $\mathrm{~g}$ \\
\hline $1 \mathbf{a}$ & $\mathrm{CH}_{3}$ & 4 & PI & $\operatorname{Poly}(1 \mathbf{a})$ & $85^{\mathrm{e}, \mathrm{f}}$ & - & \\
\hline $1 \mathbf{a} / \mathbf{2}(20)$ & $\mathrm{CH}_{3}$ & 4 & PI & $1 \mathrm{a}$ & 87 & IIa & 0.84 \\
\hline 1b & $\mathrm{CH}_{3}$ & 6 & PI & $\operatorname{Poly}(\mathbf{1 b})$ & $43^{\mathrm{e}, \mathrm{g}}$ & - & \\
\hline $1 b / 2(30)$ & $\mathrm{CH}_{3}$ & 6 & PI & $1 b$ & 97 & IIb & 0.90 \\
\hline $1 c / 2(30)$ & $\mathrm{CH}_{3}$ & 4 & SI & 1c & 99 & IIc & 0.94 \\
\hline 1d & $\mathrm{C}_{2} \mathrm{H}_{5}$ & 4 & SI & Poly(1d) & $78^{\mathrm{e}, \mathrm{h}}$ & - & \\
\hline $\mathbf{1 d} / \mathbf{2}(45)$ & $\mathrm{C}_{2} \mathrm{H}_{5}$ & 4 & SI & 1d & 80 & IId & 0.88 \\
\hline
\end{tabular}

${ }^{a}$ Monomers for polymerization in dichloromethane (DCM) at $0^{\circ} \mathrm{C}$ for $50 \mathrm{~h}$ with 0.08 molar amount of $\mathrm{BF}_{3} \mathrm{OEt}_{2}$ to monomer. Figures in parentheses show mol\% 2. ${ }^{\mathrm{b}}$ See structures of monomers in Scheme 1. In X, PI and SI refer to phthalimido and 4-succinimidophenoxy, respectively. ${ }^{\mathrm{C}}$ Based on weights of monomers in feed. ${ }^{\mathrm{d}}$ Weights of products obtained from $1 \mathrm{~g} \mathbf{I a}-\mathbf{d}$. ${ }^{\mathrm{e}}$ Obtained by reprecipitaion with DCM-methanol solvent. ${ }^{\mathrm{f}-\mathrm{h}}$ Molecular weights of uncross-linked polymers estimated by GPC based on standard polystyrenes: ${ }^{\mathrm{f}} 24500 ;{ }^{\mathrm{B}} 5700{ }^{\mathrm{h}} 8800$.

\section{Ila, IIb}

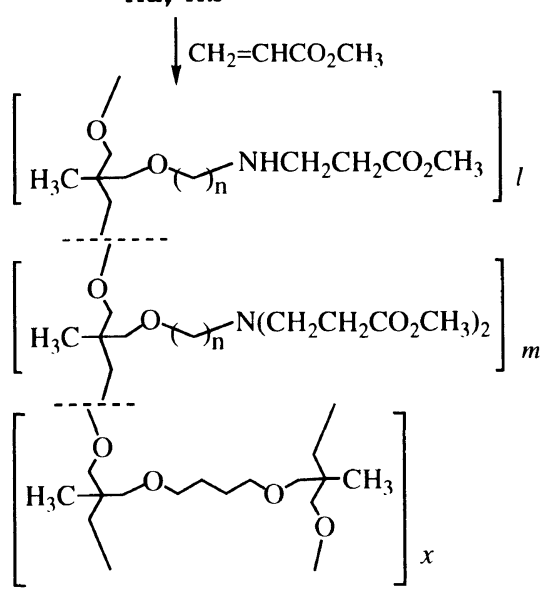

IIIa, IIIb

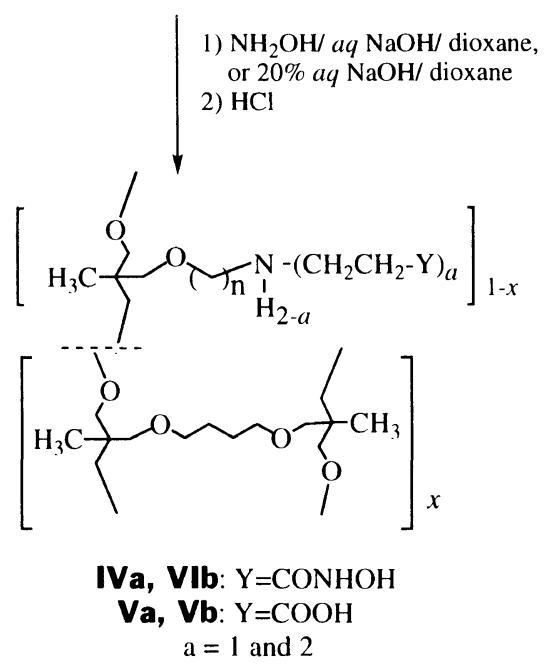

Scheme 2. Synthetic routes of polyoxetane resins, IVa and IVb, or Va and Vb from IIa or IIb through IIIa or IIIb.

in Table I.

The polymer reactions are shown in Scheme 2 for aliphatic amines of IIa and IIb, and in Scheme 3 for aromatic amines of IIc and IId. In the first step of the polymer reactions, amines of IIa - d were converted to $\beta$-aminopropionic methyl ester residues of IIIa-d by

\section{IIc, IId}

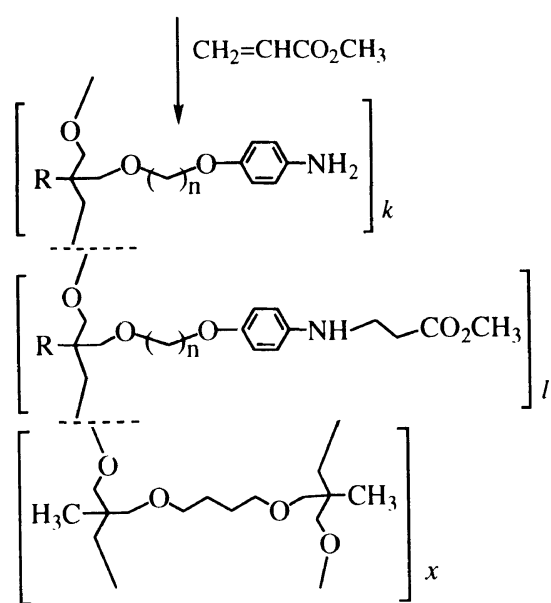

IIIc, IIId

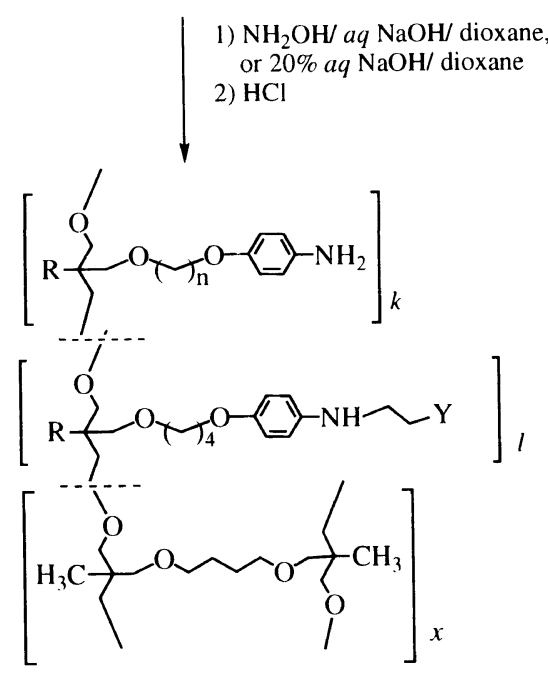

IVc, IVd: $\mathrm{Y}=\mathrm{CONHOH}$ Vc, Vd: $\mathrm{Y}=\mathrm{COOH}$

Scheme 3. Synthetic routes of polyoxetane resins, IVc and IVd, or Vc and Vd from IIc or IId through IIIc or IIId.

Michael addition reaction with excess methyl acrylate in methanol. To confirm the structure of the the Michael addition product, we examined a reaction using the anilino residue of $\mathbf{3}$, a model compound for the pendant 


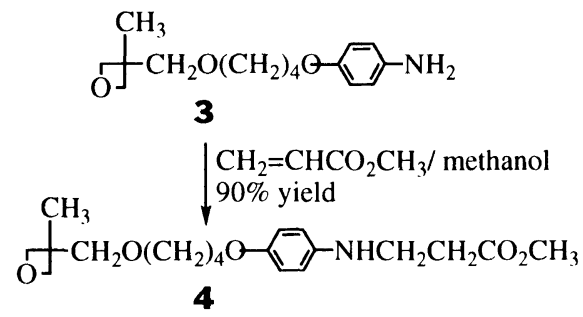

Scheme 4. Model reaction producing 4 from 3.
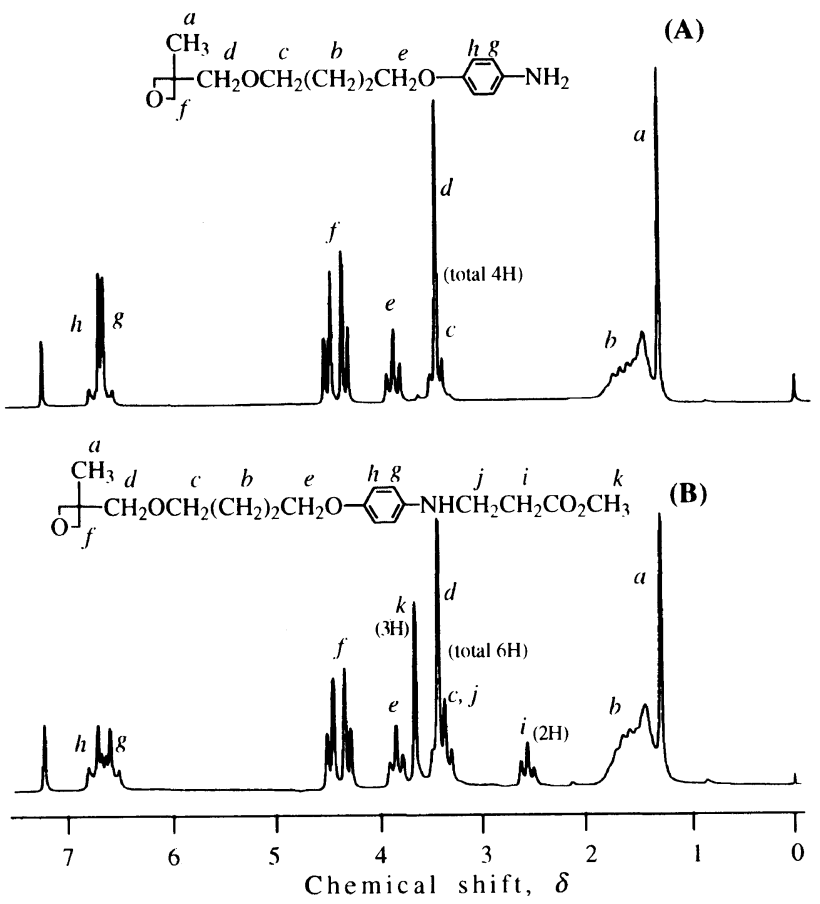

Figure 1. ${ }^{1} \mathrm{H}$ NMR spectra of $3(\mathrm{~A})$ and 4 (B).

aniline of IIc, with methyl acrylate under the same reaction conditions as for IIc, as shown in Scheme 4. This model reaction gave the single Michael addition product, 4, in $90 \%$ yield, as indicated by ${ }^{1} \mathrm{H}$ NMR (Figure 1) and IR spectra (Figure 2). In comparison with the ${ }^{1} \mathrm{H}$ NMR spectrum of $\mathbf{3}$, the spectrum of $\mathbf{4}$ indicates additional signals, (i), (j), and (k), assignable to a $\beta$ aminopropionic methyl ester moiety, at integral intensities of $2 \mathrm{H}, 2 \mathrm{H}$, and $3 \mathrm{H}$, respectively, although chemical shifts and patterns of the other signals resemble those of 3. The IR spectrum of $\mathbf{4}$ shows distinctive bands due to $\mathrm{NH}$ (amine) and $\mathrm{C}=\mathrm{O}$ (ester) stretching vibrations, respectively, at 3400 and $1740 \mathrm{~cm}^{-1}$. As shown in Figure 2, the IR spectrum of IIIc is very similar to that of $\mathbf{4}$, although the IR band assignable to the oxetane ring disappears at $980 \mathrm{~cm}^{-1}$ in the spectrum of IIIc. Hence, from results of the model reactions, it is reasonable to consider that the anilino residues of IIc are converted by polymer reaction to the single Michael addition product of IIIc, without forming the double Michael addition product. In reactions of IIa and IIb with methyl acrylate, the double Michael addition product was formed besides the single Michael addition product, as described below.

Pendant ester groups of IIIa-d were subjected to the further reaction with 3 equiv hydroxyammonium chloride in the presence of 6 equiv $\mathrm{NaOH}$ in $30 \%$ aqueous

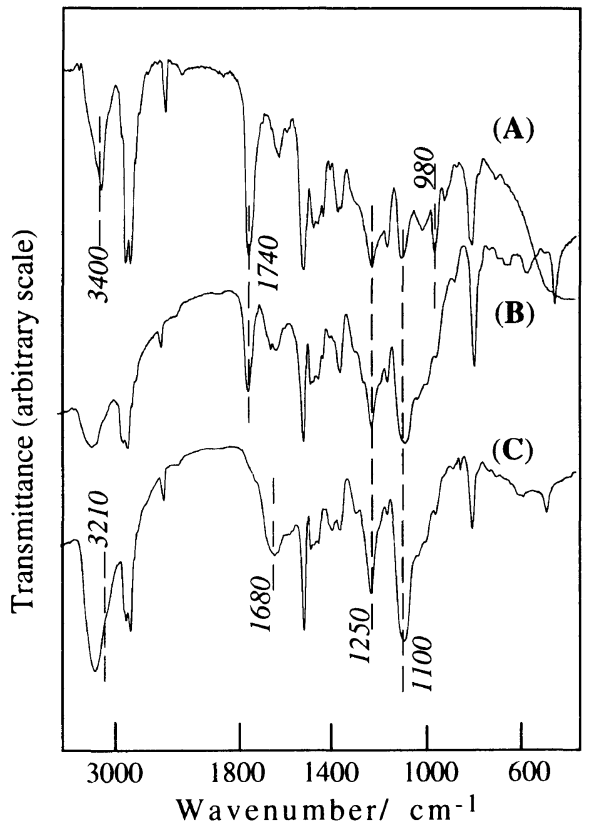

Figure 2. IR spectra of 4 (A), IIIc (B), and IVc (C)

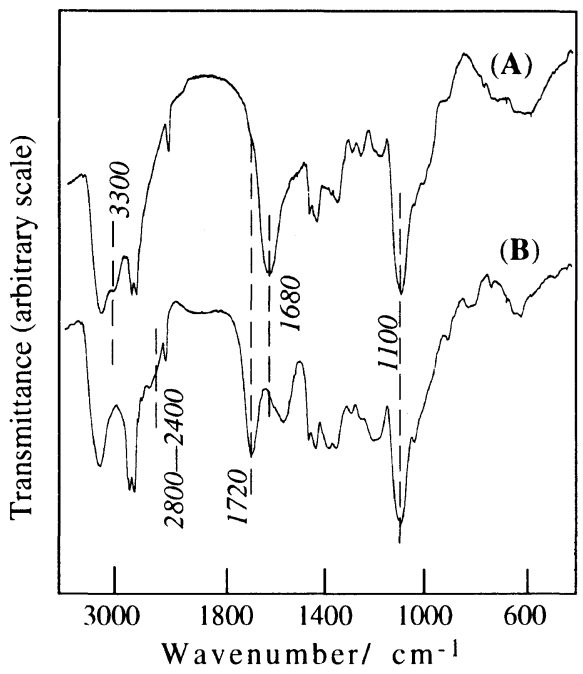

Figure 3. IR spectra of IVa (A) and Va (B).

dioxane at room temperature to give pendant hydroxamic acid residues of IVa- d. The IR spectra are exemplified in Figures 2 and 3. The IR spectra of IVa and IVc indicate a broad band due to $\mathrm{C}=\mathrm{O}$ (amide) stretching vibration at $1680 \mathrm{~cm}^{-1}$, although the band of IVc is weaker than that of IVa. A characteristic IR band of the unchanged ester is not observed at $1740 \mathrm{~cm}^{-1}$, and an IR band assignable to the $\mathrm{C}=\mathrm{O}$ stretching vibration of carboxylic acid residues also hardly appears at $1720 \mathrm{~cm}^{-1}$. The $\mathrm{NaOH}$ base is thus consumed to generate hydroxylamine from its hydrochloride, but not to hydrolyze the pendant ester. When resins IIIa-d were acidified after heating with excess $\mathrm{NaOH}$ in $50 \%$ aqueous 1,4 -dioxane at $80^{\circ} \mathrm{C}$, pendant ester groups were completely converted to the corresponding carboxylic acids of $\mathbf{V a - d}$, which showed IR bands at $1720 \mathrm{~cm}^{-1}$. When the resins were not acidified after the alkaline hydrolysis, broad bands of the sodium carboxylate at $1570 \mathrm{~cm}^{-1}$ were seen. Therefore, for resins IIIa-d, nearly all the ester groups seem to be converted to hydroxamic acid residues, i.e., $\mathrm{Y}=$ 
Table II. Polymer reaction products, IIIa-d, obtained from pendant primary amines with methyl acrylate

\begin{tabular}{|c|c|c|c|c|c|c|c|c|}
\hline \multirow{2}{*}{ Name } & \multirow{2}{*}{$\frac{\text { Yield }^{\mathrm{a}}}{\mathrm{g}}$} & \multicolumn{6}{|c|}{ Monomeric unit fractions ${ }^{b}$} & \multirow{2}{*}{$\frac{\mathrm{DF}^{\mathrm{C}}}{\%}$} \\
\hline & & & $x$ & & $k$ & $l$ & $m$ & \\
\hline IIIa & 1.42 & 0.25 & 0.32 & 0.34 & 0 & 0.48 & 0.18 & 100 \\
\hline IIIb & 1.29 & 0.35 & 0.40 & 0.40 & 0 & 0.38 & 0.22 & 100 \\
\hline IIIc & 1.37 & 0.37 & 0.37 & 0.40 & 0.46 & 0.14 & 0 & 23 \\
\hline IIId & 1.26 & 0.54 & 0.58 & 0.59 & 0.36 & 0.05 & 0 & 12 \\
\hline
\end{tabular}

${ }^{a}$ Weights of products obtained from $1 \mathrm{~g} \mathbf{I I a}-\mathbf{d}$. ${ }^{\mathrm{b}}$ See the structures in Schemes 2 and 3. Cross-linking, $x$, estimated from elemental-analysis data of imido-type resins (left), primary amino-type resins (middle), and resins of $\beta$-aminopropionate- and hydroxamic-types (right columns). ${ }^{\mathrm{c}}$ Degree of functionalization (DF) of pendant amines, $(1-x-k) /(1-x)$.

Table III. Hydroxamic and carboxylic acid-containing resins, IVa-d and $\mathbf{V a}-\mathbf{d}$, obtained by polymer reactions of the pendant $\beta$-aminopropionic esters and the $\mathrm{Cu}(\mathrm{II})$-adsorption capacities of the pendant acids

\begin{tabular}{|c|c|c|c|c|}
\hline \multirow{3}{*}{ Name } & \multirow{3}{*}{$\frac{\text { Yield }^{\mathrm{a}}}{\mathrm{g}}$} & \multicolumn{3}{|c|}{ Capacity $/ \mathrm{mmol} \mathrm{g}^{-1}$} \\
\hline & & \multicolumn{2}{|c|}{ Adsorption ${ }^{\mathrm{b}}$} & \multirow{2}{*}{$\begin{array}{c}\text { Desorption } \\
\text { Found }\end{array}$} \\
\hline & & Found & Calcd $^{\mathrm{c}}$ & \\
\hline $\mathbf{I I a}^{\mathrm{e}}$ & & 0.00 & & \\
\hline II $\mathrm{c}^{\mathrm{e}}$ & & 0.98 & & 0.96 \\
\hline IVa & $0.96(13)$ & 3.12 & $1.3-1.5$ & 2.90 \\
\hline IVb & $0.98 \quad(7)$ & 3.20 & $1.3-1.4$ & 2.97 \\
\hline IVe & $0.97 \quad(9)$ & 1.28 & 0.3 & 1.20 \\
\hline IVd & $1.05 \quad(8)$ & 0.74 & 0.1 & 0.72 \\
\hline Va & 0.92 & 1.11 & & \\
\hline Vd & 0.91 & 2.01 & & \\
\hline Vc & 0.92 & 0.95 & & \\
\hline Vd & 0.93 & 0.62 & & \\
\hline
\end{tabular}

${ }^{a}$ Weights of products obtained from $1 \mathrm{~g}$ of each resin. Figures in parentheses are considered $\mathrm{wt}_{\%} \%$ (at maximum) for moisture in products, based on elemental-analysis data. ${ }^{\mathrm{b}}$ Determined after immersing a resin in $10^{-2} \mathrm{~mol} \mathrm{dm}^{-3} \mathrm{Cu}$ (II) acetate at room temp for $48 \mathrm{~h}$. ${ }^{\mathrm{c}}$ Calculated on the basis of structure A. ${ }^{\mathrm{d}}$ After immersing a dried $\mathrm{Cu}(\mathrm{II})$-adsorbing resin in $1 \mathrm{~mol} \mathrm{dm} \mathrm{dm}^{-3}$ aqueous $\mathrm{HCl}$ at $\mathrm{rt}$ for $24 \mathrm{~h}$, amount of $\mathrm{Cu}$ (II) ions desorbed was determined for $1 \mathrm{~g}$ dried $\mathrm{Cu}$ (II)-adsorbing resin. ${ }^{\mathrm{e}}$ Obtained from Ia or Ic, as shown in Table I.

\section{$\mathrm{CONHOH}$ in IVa- $\mathbf{d}$.}

Monomeric unit fractions, $k, l$, and $x$, of IIIa (and also IVa) were calculated using elemental-analysis data for carbon and nitrogen atoms in IIIa and in IVa. Cross-linking, $x$, was calculated from elemental-analysis data of Ia and IIa. Monomeric unit fractions were obtained for IIIb - d. In each resin, $x$, calculated in three cases, were close to each other, although deviation was observed for IIIa. Thus, the pendant anilines of IIc and IId gave single Michael addition products in IIIc and IIId, respectively, in degree of functionality (DF), $(1-x-k) /(1-x)$, of 0.23 and 0.12 . The reactivity of the pendant anilines in the polymer reaction with methyl acrylate is somewhat lowered by crowded polymer matrices of IIId, which has a bulkier ethyl side chain and higher cross-linking than IIIc. The polymer reactions of the pendant aliphatic amines of IIa and IIb gave the double Michael addition product besides the single Michael addition product in IIIa and IIIb. That is, all

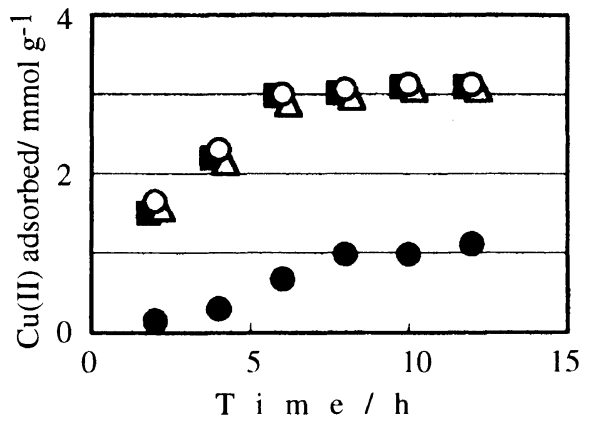

Figure 4. Plots of adsorbed $\mathrm{Cu}(\mathrm{II})$ ions against immersing time with resins: 1st $(\bigcirc)$, 2nd $(\square)$, and 3rd cycles of repeated use with IVa $(\triangle)$ and with Va $(\bigcirc)$.

the primary aliphatic amines first gave the single Michael addition product with methyl acrylate, and then 27 $37 \%$ of the resultant secondary amines were changed to give the double Michael addition product with additional methyl acrylate. The results of the polymer reactions are shown in Tables II and III. Thus, the aliphatic amines react more smoothly with methyl acrylate than the corresponding aromatic amines, presumably owing to the higher nucleophilicity of the aliphatic amines relative to that of the aromatic ones. Resins, VIa and VIb, anchor two pendant-terminal functional groups, $-\mathrm{NH}_{2-\mathrm{a}}\left(\mathrm{CH}_{2} \mathrm{CH}_{2} \mathrm{CONHOH}\right)_{a}$ where $a=1$ and 2 , and the pendant hydroxamic acid is a major functional group, whereas the pendant carboxylic acid is a minor functional group that may be neglected in comparison with that of the hydroxamic acid. When the pendant $\mathrm{CONH}_{2}$ groups based on $5 \mathrm{~mol} \% N, N^{\prime}$-methylenebisacrylamide-cross-linked polyacrylamide were allowed to react with 3 equiv hydroxyammonium hydrochloride in the presence of 1 equiv $\mathrm{NaOH}$ in water at room temperature, hydroxamic acid groups were formed in DF of $70 \%$, and $25 \%$ of the amide groups were unreacted. ${ }^{6}$ In polystyrene networks of macroreticular (20 mol\% divinylbenzene (DVB)) and gel (5-20 mol\% DVB) types, pendant ethyl malonates gave $2.0-2.9$ $\mathrm{mmol} \mathrm{g}^{-1}$ of the carboxylic acid groups and $2.1-3.7$ $\mathrm{mmolg}^{-1}$ of the hydroxamic acid groups by polymer reaction using hydroxylamine and sodium methoxide in methanol at $70^{\circ} \mathrm{C}$. The resulting resins indicated distinctive IR bands due to the carboxylic acid at $1710 \mathrm{~cm}^{-1}$, besides IR bands due to the hydroxamic acid at $1680 \mathrm{~cm}^{-1} .5$ Thus, the structures of the resins IVa-d were confirmed, and DF of polymer reactions were fairly good for aliphatic amines, although unsatisfactory for the aromatic amines.

\section{Binding Ability of Resins, IVa-d, with $\mathrm{Cu}(\mathrm{II}) \mathrm{Ion}$}

Hydroxamic and carboxylic acids bind $\mathrm{Cu}(\mathrm{II})$ ions in the form of a chelate or salt. The binding ability of pendant acid residues was examined for resins obtained in the present study. A resin was immersed in aqueous solution of $\mathrm{Cu}(\mathrm{II})$ acetate buffered at $\mathrm{pH} 6$ with sodium acetate-acetic acid, and the concentration of $\mathrm{Cu}$ (II) ions in the supernatant was determined by ethylenediaminetetraacetic acid (EDTA) titration to determine the amount of $\mathrm{Cu}$ (II) ions adsorbed on the resin. The results of the $\mathrm{Cu}(\mathrm{II})$-adsorption capacity are summarized in Table III, and plots of the amount of the adsorbed 


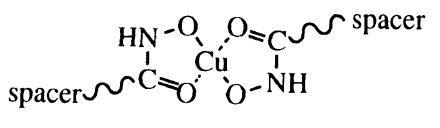

A

$$
\begin{aligned}
& \mathrm{L}_{1}=\mathrm{OCOCH}_{3}^{-}, \mathrm{OH}^{-} \\
& \mathrm{L}_{2}=\mathrm{OH}_{2}, \text { the amine and } \\
& \text { ether moieties of } \\
& \text { polyoxetane network }
\end{aligned}
$$

Scheme 5. Structures of $\mathrm{Cu}(\mathrm{II})$-complexes formed with pendant hydroxamic ligands.

$\mathrm{Cu}(\mathrm{II})$ against the immersing time, in Figure 4. As shown in Figure 4, the adsorption reaction of $\mathrm{Cu}(\mathrm{II})$ ions with resin IVa reached equilibrium so as to adsorb $3.1 \mathrm{mmol}$ $\mathrm{Cu}$ (II) ions per $1 \mathrm{~g}$ of dry IVa after $8 \mathrm{~h}$. This $\mathrm{Cu}(\mathrm{II})-$ adsorption capacity of IVa is comparable to $3.0 \mathrm{mmol}$ per $1 \mathrm{~g}$ dry resin obtained as a hydrophilic gel of poly(acrylohydroxamic acid) cross-linked with $5 \mathrm{~mol} \% \mathrm{~N}, N^{\prime}$ methylenebisacrylamide. ${ }^{6}$

In the ordinary form of chelating $\mathrm{Cu}$ (II) ions with hydroxamic acids, such as acetohydroxamic acid, two molecules of hydroxamic ligands should bind to one molecule of the $\mathrm{Cu}(\mathrm{II})$ ions, as shown by structure $\mathrm{A}$ in Scheme $5 .{ }^{4}$ In each resin, the amount of $\mathrm{Cu}$ (II) ions adsorbed was higher than the capacity calculated for structure A on the basis of content of the pendant hydroxamic acids. Therefore, uncompleted structures, such as $\mathrm{B}$, may be formed with ligands $\mathrm{L}_{1}$ and $\mathrm{L}_{2}$ other than the pendant hydroxamic acid groups. The aliphatic amine and ether moieties of IIa and IIb may not act for ligand binding $\mathrm{Cu}(\mathrm{II})$ ions, since IIa adsorbed no $\mathrm{Cu}(\mathrm{II})$ ions dissolved in water at $\mathrm{pH}$ 6. Yokoi et al. studied interactions between $\mathrm{Cu}(\mathrm{II})$ ions and poly(acrylic acid) (PAA) in aqueous solution. At $\mathrm{pH} 3-8$, mononuclear $\mathrm{Cu}(\mathrm{II})$ complexes with one and two carboxyl groups of PAA always were found to exist in equilibrium between these complex species, and these two complexes have the same coordination structures as the low-molecularweight acetate complexes $\mathrm{Cu}(\mathrm{II})(\mathrm{OAc})^{+}$and $\mathrm{Cu}(\mathrm{II})-$ $(\mathrm{OAc})_{2}$, where OAc denotes acetate anions, suggesting that coordination of $\mathrm{Cu}(\mathrm{II})$ ions to carboxyl groups of PAA is strain-free. ${ }^{7}$ Thus, the structures A and B may exist in $\mathrm{Cu}(\mathrm{II})$-complex formation with ligands of the present polyoxetane resins. In such a case, structure B may be formed more easily than structure $A$, since, in the formation of intermolecularly chelated structure of $\mathrm{A}$, the coordination of pendant ligands to $\mathrm{Cu}$ (II) ions is blocked by the cage of polymer matrices and the polymer backbones are pressed to take deformed conformations, which are strained, possibly due to restrained movability of polymer backbones by cross-linking. IIc could adsorb $\mathrm{Cu}$ (II) ions from water at $\mathrm{pH} 6$, indicating that the aromatic amines were ligands capable of binding to $\mathrm{Cu}(\mathrm{II})$ ions. Poly(4-aminostyrene) acts as a polymeric ligand for the formation of several $\mathrm{Co}$ (III) complexes. $^{8}$ Judging from a comparison of capacity of IVc and IIc, most adsorbed $\mathrm{Cu}$ (II) ions appear to bind to aromatic amines.
Carboxylic acids $\mathbf{V a}$ and $\mathbf{V b}$ adsorbed 1.1 and $2.0 \mathrm{mmol}$ $\mathrm{Cu}(\mathrm{II})$ ions per g-resin, respectively. These values are very inferior to those observed with the hydroxamic acids of IVa and IVb. The carboxylic acids of Vc adsorbed $0.95 \mathrm{mmol} \mathrm{Cu}$ (II) ions per g-resin, which was very close to capacity, $0.98 \mathrm{mmol}$ per g-resin, for $\mathrm{Cu}$ (II)-adsorption with IIc. At this time, why the pendant carboxylic acids indicate lowered $\mathrm{Cu}(\mathrm{II})$-capacity is not clear.

When immersed in aqueous solution of $\mathrm{Cu}(\mathrm{II})$ acetate, hydroxamic acid-containing resins, IVa and IVb, were colored from white to green, and carboxylic acidcontaining resins, $\mathrm{Va}$ and $\mathbf{V b}$, from white to blue, although such color changes were not observed for aromatic resins, IVc, IVd, Vc, and Vd, since these resins are dark brown. $\mathrm{Cu}(\mathrm{II})$-adsorbing IVa-IVd indicated broad bands at $1620-1600 \mathrm{~cm}^{-1}$, but not IR bands at $1680 \mathrm{~cm}^{-1}$ due to amide groups of IVa-IVd. The hydroxamic acid residue is thus a major binding group in chelating resins of aliphatic-amino types, IVa and IVb. This was proved from observation of IR spectra of IVa and IVb.

The $\mathrm{Cu}(\mathrm{II})$-adsorbing resins were immersed in dilute hydrochloric acid for $20 \mathrm{~h}$ to completely desorb $\mathrm{Cu}$ (II) ions, to an extent comparable to that on the virgin resin. The resin recovered was used to adsorb $\mathrm{Cu}$ (II) ions again. Repeated use results of IVa are shown in Figure 4.

Polyoxetane resins anchoring pendant spacer-separated hydroxamic and carboxylic acid moieties were readily prepared with high DF through polymer reaction steps using methanol, ethanol, and aqueous 1,4-dioxane solvents, poor solvents for polystyrene resins widely used as supporting matrices in functional polymers synthesis. This is ascribed to the flexibility and moderate polarity of polyether networks, which swell in protic and aqueous organic solvents. When such pendant groups as hydroxamic and carboxylic acids and aromatic amines were anchored to polyoxetane resins, the supporting matrices could take $\mathrm{Cu}$ (II) ions even from water. This behavior of supporting matrices is facilitated by the expansion of polyether networks rather than hydrophilicity, which may be much lowered (see below), i.e., they expand enough to interfuse hydrated ionic species into networks from aqueous media by attraction between pendant ligands and ions.

Diethyl ether shows solubility in water comparable to that of 1-butanol, i.e., both are soluble to the extent of about $8 \mathrm{~g}$ per $100 \mathrm{~g}$ water. ${ }^{9}$ However, it is difficult to dissolve ethers with bulkier or longer alkyl groups in water, e.g., diisopropyl and dibutyl ethers are hardly soluble in water. A resin of 3-(4-bromobutoxy)methyl3 -methyloxetane cross-linked with $30 \mathrm{~mol} \%$ of 2 , considered as a model of supporting matrices for resins obtained in this study, did not seem to swell in water. This resin is composed of ether moieties analogous to ethers with neopentyl and butyl groups.

Uncross-linked polyoxetanes with the pendant $\mathrm{NH}_{2}$ groups, e.g., IIa and IIb with $x=0$, were soluble in water, ${ }^{2}$ obviously due to the hydrophilicity of $\mathrm{NH}_{2}$ groups immobilized on polymer backbone. Thus, pendant hydrophilic groups, such as $\mathrm{NH}_{2}, \mathrm{CONHOH}$, and $\mathrm{CO}_{2} \mathrm{H}$, may be important to interfuse aqueous media into the hydrophobic resin.

Glass transition temperatures $\left(T_{\mathrm{g}}\right)$ of several poly- 
oxetanes having alkyl side chains at the $\mathrm{C}-3$ position of the oxetane unit were determined to be below $0^{\circ} \mathrm{C}, e . g$., $T_{\mathrm{g}}$ of $-31^{\circ} \mathrm{C}$ was reported for poly(3-methyl-3-propyloxetane), which may be regarded as a model for the main chain part of resins used in this study. ${ }^{10}$ We confirmed that 3-(4-bromobutoxy)methyl-3-methyloxetane gave a viscous grease-like polymer under ring-opening polymerization conditions, probably, showing that $T_{\mathrm{g}}$ of this polymer is below room temperature. ${ }^{11}$ Thus, polyoxetane chains become flexible, although exceptions have been found, as in the case of crystalline polymers of 3,3-dimethyl- and 3,3-diethyloxetanes and so on. ${ }^{12-14}$

Oxetane monomers having functional groups of amines and $N$-unsubstituted amides at the side chain-end could not give the corresponding polymers by $\mathrm{BF}_{3}$ initiated ring-opening polymerization, possibly due to character of the amino and amido nitrogen atoms, which interfere with the initiation step with $\mathrm{BF}_{3}$ through Lewis acid-base interaction. Ring-opening polymerization with $\mathrm{BF}_{3}$ was quite unsusceptible to phthalimide and $N$ phenylsuccinimide moieties of oxetane monomers. Therefore, pendant aliphatic and aromatic amines anchored to polyoxetane networks through spacers can be prepared with varied cross-linking.

In conclusion, pendant primary aliphatic amines immobilized in flexible, expansible polyoxetane networks are considered as reaction sites useful for producing various functional polymers, although the corresponding aromatic amines must be further investigated to improve the DF of polymer reactions.

\section{EXPERIMENTAL}

\section{Materials}

Polyoxetane resins, $\mathbf{I a}-\mathbf{d}$, were obtained by $\mathrm{BF}_{3^{-}}$ initiated ring-opening polymerization of oxetanes $\mathbf{1 a - d}$ with a cross-linking agent, $\mathbf{2}$, and then the pendant imides of Ia-d were completely converted to the corresponding primary amines of IIa-d using hydrazine monohydrate in ethanol at $50^{\circ} \mathrm{C}$ or using $20 \% \mathrm{NaOH}$ in $50 \%$ aqueous 1,4-dioxane at $80^{\circ} \mathrm{C} .^{2,3}$ The elemental analysis data of the products are as follows.

Anal. (Found). Ia: C, 66.01\%; N, 3.55\%. Ib: C, $67.09 \% ; \mathrm{N}, 2.96 \%$. Ic: C, $65.37 \% ; \mathrm{N}, 3.27 \%$. Id: C, $65.21 \%$; N, 2.09\%. IIa: C, 61.12\%; N, 4.55\%. IIb: C, $64.67 \%$; N, 3.69\%. IIc: C, 64.99\%; N, 3.27\%. IId: C, $53.61 \%$; N, $5.76 \%$.

Resins with the Pendant $\beta$-Aminopropionic esters; Typical Procedure. Resin IIa $(2.88 \mathrm{~g}$, about $1.0 \mathrm{mmol}$ of the pendant $\left.\mathrm{NH}_{2}\right)$ was stirred in methanol $\left(35 \mathrm{~cm}^{3}\right)$ at room temperature for $1 \mathrm{~h}$, and then methyl acrylate $(1.8 \mathrm{~g}, 21 \mathrm{mmol})$ was added into the resin dropwise at $0^{\circ} \mathrm{C}$. The contents were stirred at room temperature for $20 \mathrm{~h}$. The resultant resin was filtered, washed successively with methanol and ether, and then dried in a vacuum. The products gave the following elemental-analysis data.

Anal. (Found). IIIa: C, 59.66\%; N, 3.25\%. IIIb: C, $61.88 \%$; N, 2.79\%. IIIc: C, $62.01 \%$; N, 2.86\%. IIId: C, $57.27 \% ; \mathrm{N}, 1.82 \%$.

The anilino group of $3^{3}$ was also allowed to react with the acrylate in the same manner as the above-mentioned procedure, and the crude product was purified by column chromatography to give 4 as a viscous oil in a $90 \%$ yield. The structure of $\mathbf{4}$ was confirmed by its ${ }^{1} \mathrm{H}$ NMR and IR spectra, shown in Figures 1(B) and 2(A), respectively.

Resins with the Pendant Hydroxamic and Carboxylic Acids; Typical Procedure. Resin IIIa (1.53 g, about $4.6 \mathrm{mmol}$ of the pendant ester) was stirred in a mixture of 1,4-dioxane $\left(15 \mathrm{~cm}^{3}\right)$ and water $\left(3 \mathrm{~cm}^{3}\right)$ at $40^{\circ} \mathrm{C}$ for $1 \mathrm{~h}$, and hydroxyammonium chloride $(0.92 \mathrm{~g}, 13.3 \mathrm{mmol})$ was added into the contents. A $6 \mathrm{~mol} \mathrm{dm}^{-3}$ aqueous $\mathrm{NaOH}$ solution $\left(4.5 \mathrm{~cm}^{3}\right)$ was added dropwise into the resin with stirring at $0^{\circ} \mathrm{C}$, and the mixture was stirred at $0^{\circ} \mathrm{C}$ for $1.5 \mathrm{~h}$ and then at room temperature for $7.5 \mathrm{~h}$. After removing the solvent by means of an evaporator, the residue was acidified at $\mathrm{pH} 4$ with diluted $\mathrm{HCl}$, filtered, washed successively with water and methanol, and dried under vacuum to give resin IVa. The products gave the following elemental-analysis data.

Anal. (Found). IVa: C, 49.94\%; N, 7.33\%. IVb: C, $55.34 \%$; N, 6.74\%. IVc: C, $60.91 \%$; N, 3.49\%. IVd: C, $61.30 \%$; N, $2.81 \%$.

Carboxylic acid-containing resins, Va-d, were obtained by alkaline hydrolysis of IIIa - $\mathbf{d}$ with an excess of $\mathrm{NaOH}$ in $50 \%$ aqueous 1,4 -dioxane at $80^{\circ} \mathrm{C}$ for $24 \mathrm{~h}$, followed by the same post-treatment as that for IVaIVd.

\section{Adsorption of $\mathrm{Cu}(I I)$ with the Pendant Ligands of Resins}

The typical procedure is as follows. Dried resin, IVa, $(0.1 \mathrm{~g})$ was placed in an $100 \mathrm{~cm}^{3}$-graduated flask containing $50 \mathrm{~cm}^{3}$ of a buffer solution (sodium acetateacetic acid) at $\mathrm{pH} 6$ overnight. Into this flask, $10 \mathrm{~cm}^{3}$ of a $0.1 \mathrm{moldm}^{-3}$ aqueous solution of $\mathrm{Cu}(\mathrm{II})$ acetate and an adequate volume of the buffer solution were added to adjust the solution volume at the marked line. Aliquots (each $5 \mathrm{~cm}^{3}$ ) were drawn out from the supernatant of the solution at appropriate intervals of immersing time to determine the amount of the $\mathrm{Cu}(\mathrm{II})$ ion adsorbed on the resin by an EDTA titration method, till the chelation reaction reached its equilibrium state. The $\mathrm{Cu}(\mathrm{II})$-adsorbing resin was collected by filtration, and immersed in an $1 \mathrm{~mol} \mathrm{\textrm {dm } ^ { - 3 }}$ aqueous $\mathrm{HCl}$ solution $\left(10 \mathrm{~cm}^{3}\right)$ for $20 \mathrm{~h}$ to determine the amount of the $\mathrm{Cu}$ (II) ion desorbed from the resin. The recovered resin was repeatedly examined in three cycles of the adsorptiondesorption for the $\mathrm{Cu}(\mathrm{II})$.

\section{REFERENCES}

1. M. Motoi, Kobunshi Kakoh (Polymer Applications), 39, 59 (1990); ibid., 44, 12 (1995).

2. M. Motoi, S. Sekizawa, K. Asakura, and S. Kanoh, Polym. J., 25, 1283 (1990)

3. Y. Xu, S. Kanoh, and M. Motoi, Reactive \& Functional Polym., 37, 65 (1998).

4. T. Nozawa, Y. Nose, M. Hatano, and S. Kambara, Makromol. Chem., 112, 73 (1968).

5. T. Hirotsu, S. Katoh, K. Sugasaka, K. Ichimura, Y. Suda, M. Fujishima, Y. Abe, and T. Misonoo, J. Polym. Sci., Polym. Chem. Ed., 24, 1953 (1986).

6. A. J. Domb, E. G. Cravalho, and R. Langer, J. Polym. Sci., Polym. Chem. Ed., 26, 2623 (1988).

7. H. Yokoi, S. Kawata, and M. Iwaizumi, J. Am. Chem. Soc., 108, 3361 (1986).

8. E. Tsuchida, H. Nishide, and M. Takeshita, Makromol. Chem., 175, 2293 (1974). 
9. R. T. Morrison and R. N. Boyd, "Organic Chemistry," 6th ed, Prentice-Hall international, Englewood Cliffs, New Jersey, 1992, p 238.

10. E. Pérez, A. Bello, and J. M. Pereña, Polym. Bull., 20, 291 (1988)

11. M. Motoi, S. Nagahara, M. Yokoyama, E. Saito, O. Nishimura,

S. Kanoh, and H. Suda, Bull. Chem. Soc. Jpn., 62, 1572 (1989).

12. H. Tadokoro, Y. Takahashi, Y. Chatani, and H. Kakida,
Makromol. Chem., 109, 96 (1967).

13. M. A. Gómez, J. G. Fatou, and A. Bello, Eur. Polym. J., 22, 43 (1986).

14. K. E. Hardenstein, G. V. S. Henderson, Jr., L. H. Spering, C. J. Murphy, and G. E. Manser, J. Polym. Sci., Polym. Phys. Ed., 23, 1597 (1985). 